\title{
Política de Pessoal Para o Desenvolvimento *
}

\section{Glauco Lessa de Abreu e Silva \\ Diretor-Geral do DASP}

Objetivo-síntese da ação do Governo, expresso no Plano Nacional de Desenvolvimento, é "colocar o Brasil, no espaço de uma geração, na categoria das nações desenvolvidas".

Esse objetivo há de alcançar-se mercê de modelo nacional, próprio, que importa tanto na criação de economia moderna, competitiva e dinâmica como na realização de democracia econômica, social, racial e política, segundo os sentimentos nacionais.

Procura-se, assim, imprimir à vida brasileira o ritmo necessário de atualização tecnológica e de aplicação racional e programada de recursos materiais e humanos, para o estabelecimento de processo competitivo ao nível econômico e integrativo ao nível social, o primeiro assegurando índices satisfatórios de eficiência nos setores de produção e o segundo harmonizando governo e empresários, empresários e trabalhadores, regiões desenvolvidas e regiões em desenvolvimento.

O Homem, entretanto, não sendo mero espectador desse processo, mas, pelo contrário, protagonista dele, precisa ser preparado para desempenhar o seu papel, uma vez que, em nossa civilização, o desenvolvimento está condicionado à aplicação do conhecimento, isto é, verifica-se em bases tecnológicas.

Por tudo isso uma política de aproveitamento dos recursos humanos como fator de produção e de consumo inseriu-se entre

\footnotetext{
Conferencia pronunciada na Academia Nacional de Policia, durante o V Curso Superior de Policia, a convite do Departamento de Policia Federal, do Ministério da Justiça. 
as metas e bases da ação governamental para sustentar, permanentemente, a expansão industrial e comercial já alcançada.

Daí por que se procura integrar juventude, intelectuais, profissionais de todas as atividades, servidores públicos e demais categorias sociais na construção do Brasil que todos desejamos, de modo a auferir em grau máximo o rendimento do capital humano nacional.

Pragmatizando esta decisão, a Educação em todos os niveis e em todos os campos constitui preocupação constante, pois é através dela que se obtém a necessária incorporação e atualização de conhecimentos e a modernização de métodos de trabalho, capazes de manter o progresso no grau de aceleração desejável. Não só educação em todos os níveis e em todos os campos, mas também reeducação, porque o País não necessita apenas de educar, senão igualmente de reeducar; de maneira que os destinatários desse cuidado governamental não são exclusivamente os que se vão iniciar ou estão se iniciando nas atividades de produção de bens ou serviços públicos ou não, mas também aqueles que, já se encontrando no exercício delas, poderão, através de treinamento especial, melhorar seu desempenho, elevando os níveis de rendimento do seu trabalho não só para si próprios como para a coletividade. E o Governo não se limita a incentivar, mas patrocina diretamente atividades educacionais, como o Programa Nacional de Treinamento de Executivos e o Programa Intensivo de Preparação da Mão-deObra.

Nítida demonstração de que a escassez de capital financeiro e, conseqüentemente, de capital físico, já não é fator restritivo do desenvolvimento é representada pelas medidas recentemente adotadas na área econômica, tendentes a dimiauir o influxo de recursos do Exterior, limitando a sua oferta. Se a situação já permite que procuremos manter esse influxo sob controle é porque o fator a ser ativado no sistema é o capital humano, isto é, o valor produtivo do cidadão, adquirido pela educação escolar ou profissional, pela experiência de desempenho e pelo conhecimento de questões brasileiras.

Essa capacitação em nível ótimo do capital humano importa na permanente atualização de métodos e processos, de modo a promover sua adequação sistemática às necessidades de produção, e assim, permitir o aproveitamento integral das potencia- 
lidades de desenvolvimento em todos os campos de atividade e em todas as regiões do País.

Tal aproveitamento será apoiado pelo Plano Básico de Desenvolvimento Científico e Tecnológico, no qual se define a política nacional nesse importante setor, em que se abrem para - Homem de nossa época desafios cada vez mais sérios e que, por outro lado, é vital para a obtenção de melhores condições de vida. Os investimentos nesse campo serão da ordem de $10 \%$ do Orçamento em 1974 e representam mais que o total investido pela ONU nos países em desenvolvimento, relativa. mente às áreas tecnológicas e de pesquisa científica.

É justamente para dar ao avanço tecnológico sobre a socie. dade moderna um sentido humanista que o treinamento se constitui condicionante do futuro do País: o crescimento demográfico, a necessidade de ampliar a produção de alimentos, o desemprego, o próprio progresso tecnológico em si, a urbanização, a poluição ambiental, os valores em mudança na sociedade exigem a cada passo do Administrador Público e do empresariado em geral ajustamento de conhecimentos e criatividade, de modo a minimizar os efeitos dessas pressões sobre o indivíduo, aplicando a cada situação os conhecimentos disponíveis mais recentes, no seu significado mais positivo para o homem.

$\mathrm{Na}$ área específica da Administração Pública, a dinâmica do processo desenvolvimentista requer das instituições elevada capacidade de atendimento a exigências as mais cambiantes, diversificadas e complexas. Daí por que se implanta uma ampla e total reforma administrativa que, baseando a ação do administrador nos princípios fundamentais de planejamento, coordenação, descentralização, delegação de competência e controle, dê à máquina burocrática a energia necessária ao acompanhamento das necessidades operacionais e técnicas que the são inerentes. A ação administrativa entrou, assim, num compasso de planejamento em programas plurianuais gerais, setoriais e regionais, apoiados em orçamentos-programa, com execução totalmente coordenada nos diversos niveis administrativos, todos eles, no exercício de suas atribuições, investidos e exercitantes de sua parcela de responsabilidade, controladores dos órgãos sob sua subordinação e submetidos, por seu turno, ao controle de seus subordinantes, dentro da modalidade sistêmica de operação, em cada área de atividades. 
Tal modelo administrativo - , podemos testemunhar à vista do que vem ocorrendo na área de Administração de Pessoal está conscientizando as chefias setoriais e regionais, agora efetivamente participantes, autônomas e responsáveis.

$\mathrm{Na}$ verdade, o Sistema de Pessoal Civil, coordenado por uma Comissão constituída do dirigente do órgão central - seu presidente nato - e dos dirigentes dos órgãos setoriais, além de um representante do Ministério do Planejamento e Coordenação Geral, tem proporcionado ao governo a identificação de aspectos do problema de Administração de Pessoal que só esse contato direto com os fatos através dos Diretores da especialidade em todas as áreas da Administração possibilitaria. E conhecer um problema, conhecê-lo bem, é fator primordial no encaminhamento de soluções acertadas.

Estabeleceu-se através da modalidade sistêmica de operação a atuação integrada da Administração e o embasamento realista para a resolução da problemática de cada setor, uma vez que da busca de soluções participa diretamente o responsável pela área a ser tratada.

Verdade, porém, que semelhante sistema de operação acentua ainda mais a qualificação do elemento humano como requisito essencial para o êxito dos empreendimentos programados.

É sabido, entretanto, que, para motivar o funcionário e mantê-lo participante, todas as atividades básicas da Administração de Pessoal devem ser acionadas; desde o recrutamento e a seleção, para atrair e aproveitar os melhores, passando pelo treinamento, o aperfeiçoamento, até a remuneração e os estímulos funcionais para conservá-los a serviço da Administração Pública.

Atenta a esse fato, a Revolução de 64 fixou, no próprio ato de diretrizes para a Reforma Administrativa, as linhas mestras de sua política de pessoal, voltada marcadamente para a valorização e dignificação da função pública, e o aumento da produtividade, mediante o estabelecimento da profissionalização, o fortalecimento do sistema do mérito, a avaliação realista de cargos e a constituição de quadros dirigentes, por meio de formação e aperfeiçoamento de administradores. Previu, ainda, a criação de um órgão exclusivamente destinado ao recrutamento, seleção e aperfeiçoamento de pessoal para as mais altas funções de assessoramento à Administração Civil. 
A aplicação prática desses princípios teve início com a promulgação das diretrizes para o novo Plano de Classificação de Cargos, após aprofundados estudos realizados por técnicos altamente capacitados, integrantes do próprio Serviço Público e também do setor empresarial, especialmente chamados a essa tarefa pelo Governo, que os designou em Comissão de Reforma.

Dentre essas diretrizes merecem destaque especial, pelo seu aspecto diretamente ligado ao processo desenvolvimentista, a flexibilidade do sistema e o treinamento abrangente.

Com efeito, trata-se de um plano de múltiplas possibilidades de rápida adaptação a novas necessidades ou situações. Inteiramente acionado pelo Poder Executivo nas suas prerrogativas constitucionais, possibilita não só o desdobramento dos Grupos de Categorias Funcionais como a criação de outros Grupos, segundo a necessidade da Administração, e coloca, igualmente, sob a competência do Executivo o estabelecimento de critérios seletivos específicos para cada Grupo, a proposição de níveis de retribuição, a estruturação dos próprios Grupos e a escala de prioridades para a implantação. Do mesmo modo a avaliação de cargos situa-se na esfera executiva e obedece, igualmente, ao princípio da flexibilidade. Assim é que as escalas de retribuição, cuja elaboração se apóia nos princípios definidos para a política salarial, vêm sendo fixadas pela avaliação objetiva da atividade em cogitação, dentro de um relacionamento integrado com todas as demais, porém independentemente de cada uma delas. Isto dará possibilidade de correção de retribuição para ajustamento às flutuações do mercado de trabalho com referência a determinado cargo, sem que haja necessidade de se alterar a retribuição de outro que apenas lhe seja assemeIhado.

Essa flexibilidade extrínseca, ademais, não se limita a uma permanente adaptabilidade aos programas, senão porque alcança o estabelecimento de melhor ajustamento do funcionário no regime de classificação, permitindo-lhe colocar-se ao nível de sua formação profissional, se isto atender aos interesses da repartição, independentemente das atividades que venha executando. Assim, aquele que durante anos procurou aperfeiçoarse, galgou nível de escolaridade mais elevado, cursou universidade, porém teve de manter-se, por força de um sistema rígido, em atividades da mesma natureza daquelas em que se iniciara 
no Serviço Público, vê agora alargarem-se suas perspectivas, na possibilidade de materialização de suas legítimas aspirações profissionais.

Caracterizando-se como documento aberto, o Plano de Classificação de Cargos poderá dilatar-se ou restringir-se na medida em que as necessidades dos programas assim o indicarem, permanecendo sempre em condições satisfatórias de atendimento aos objetivos da Administração.

Outro aspecto que merece destaque especial é o de sua operacionalidade intrínseca, representada pela fixação de critérios seletivos para o progresso funcional, associados a um sistema de treinamento e qualificação destinado a assegurar a permanente atualização e elevação do nível de eficiência do funcionário.

Com efeito, é o treinamento que, permanentemente articulado com o conteúdo ocupacional dos cargos que estão na linha de ascensão do funcionário, condiciona as etapas de seu progresso funcional e permite-lhe galgar as linhas intermediárias de comando, já então mediante cursos supletivos destinados a dar-lhe capacidade para o exercício dessa atividade específica. Atingida a etapa final da categoria, em nível universitário, o funcionário passará a constituir clientela de outro tipo de treinamento, este em grau de formação para exercício de atividades de assessoramento superior à Administração Civil, a cargo do Centro de Aperfeiçoamento de que se tratará adiante.

Será, assim, um treinamento por objetivos, inteiramente orientado para as finalidades da Administração. A correlação entre os programas de treinamento e as metas da organização é exatamente o que o distingue da educação, de modo genérico: esta se caracteriza pela "transmissão de conhecimento porém sem relação específica com determinado papel, função, organização ou sistema" e nela "transmitir conhecimento, ou melhor ainda, promover a oportunidade de o educando descobrir o conhecimento, pode ser considerado um fim em si mesmo". No treinamento, a transmissão de conhecimentos, habilidades e atitudes deve visar diretamente à melhoria dos padrões de desempenho profissional dentro da organização.

O novo Plano de Treinamento vem sendo elaborado de acordo com uma estratégia apoiada, basicamente, nos seguintes princípios: 
- correlação funcional com o cargo ocupado pelo funcionário, de modo a promover seu perfeito ajustamento às tarefas que the compete executar, reforçando o princípio da profissionalização;

- acoplamento com os programas do Plano Nacional de Desenvolvimento, a fim de atender, com tratamento preferencial, às áreas e às atividades prioritárias em razão das metas ali estabelecidas;

- integração ao recrutamento e à seleção, dentro da modalidade sistêmica de operação;

- aproveitamento dos recursos educacionais existentes no País, através de contrato, pela repartição interessada e dentro de suas disponibilidades orçamentárias, com Instituições públicas ou particulares integrantes da rede educacional, que será, deste modo, incorporada ao instrumental do Treinamento do Pessoal Civil, ampliando-se a capacidade e reduzindo-lhe o custo. Trata-se de aproveitamento de experiência já avaliada, aplicável notadamente nas áreas de pesquisa, tecnologia e formação de pessoal técnico especializado, quer de nível superior, quer de nível médio.

O Treinamento se constituirá em prolongamento do critério do mérito, que acompanhará toda a trajetória do funcionário, caracterizando, para este, um sistema altamente democrático, que lhe permitirá colocar-se ao nível de sua real capacidade na hierarquia da repartição, e, para a Administração, a garantia de constituição de equipes sempre as melhores.

A instituição de treinamento avançado criado pelo Decretolei $n$. $200 / 67$, destinado a recrutar e preparar pessoal para a direção e assessoramento superiores do Serviço Público Civil, tarefa ali distribuída ao Centro de Aperfeiçoamento, mereceu destaque na Mensagem do Excelentíssimo Senhor Presidente da República ao Congresso Nacional, no início deste ano, e tomou forma definida com o respectivo projeto arquitetônico cujas obras já se encontram em pleno desenvolvimento.

A conclusão da primeira fase do aludido projeto, prevista para o próximo ano, já permitirá que o Centro entre em operação com um contingente de duzentos treinandos em regime residencial. 
Numa área de quatrocentos mil metros quadrados, o plano da Instituição se divide em quatro grandes setores, a saber: o de ensino, o comunitário, o residencial e o de serviços gerais. Tais setores, embora intimamente relacionados no esquema da comunidade, operam de modo autônomo, dada à natureza, as características e as finalidades específicas de cada um.

O método de ensino, o regime disciplinar e o plano de trabalho e de vida social a serem adotados no CENDAP visarão, acima de tudo, a criar uma consciência comum relativamente a diretrizes, doutrina, objetivos e programas de Governo e Administração no grupo dos que, submetidos a treinamento na Instituição, venham a compor a reserva de valores humanos recrutáveis para a direção e o assessoramento superiores, com o que se eliminará, a curto prazo, o amadorismo e a improvisação nesse campo.

Essa política de qualificação dos recursos humanos como meio de motivar o funcionário, integrá-lo ao processo, melhorar seus níveis de eficiência, mantê-lo a serviço da Administração Pública e, através de seu desempenho, alcançar os objetivos nacionais de desenvolvimento e integração social, evoluirá em bases científicas, com o ingresso do órgão central do Sistema de Pessoal Civil no campo da pesquisa aplicada. É o que se cuida de fazer, após identificar a necessidade de montagem de mecanismo capaz de investigar e propor fórmulas alternativas para resolver as inúmeras questões com que se defrontam hoje os escalões superiores da Administração Civil. A política de pessoal se revestirá, assim, de caráter eminentemente técnico-científico, que é, na verdade, a tônica dos Governos da Revolução e a cuja conta corre o nosso desenvolvimento.

Senhores, como está demonstrado pelos recentes atos emanados dos Poderes Executivo e Legislativo, vem-se concretizando, de 67 a esta parte, uma nova concepção de estruturação de recursos humanos em que a meta é aquela que conduz a todas as outras: a meta é o HOMEM. Porém, na situação especial e única de agente o objeto de mudança a um só tempo, o homem é também instrumento. Assim, é o próprio titular da função pública, em última análise, o responsável pela sua dignificação e valorização, pois é através da atuação concreta e empenhada do funcionário - "sistema circulatório da ação governamental", segundo as palavras do Excelentissimo Senhor Presidente da República - que o cargo público assume exis- 
tência real e atinge a sua finalidade de dar versão concreta aos programas.

Conscientizemos seu significado nesta era em que vivemos: - cargo público, que no Império foi símbolo de "status" social e, na República Velha, de "status" político, será para os brasileiros que têm a honra de viver o momento histórico da arrancada desenvolvimentista verdadeiro símbolo de civismo, pois dele só advém um tipo de prestígio: o de servir ao Brasil, servindo ao seu povo.

Congratulo-me com o Departamento de Polícia Federal e com esta Academia pela realização de mais um curso Superior de Polícia, visando à preparação e atualização de pessoal para - exercício de elevados postos na estrutura policial, responsável pela segurança nacional interna - um dos pressupostos da auto-sustentação do processo desenvolvimentista - , criadora e mantenedora do clima de ordem e tranqüilidade indispensável à consecução do ideal nacional, que nesta importante fase da nossa história alenta o povo brasileiro na construção de um Brasil ainda maior.

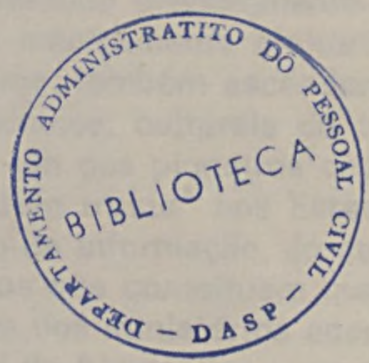


